\title{
Long-term mental health and social support in victims of disaster: comparison with a general population sample - ERRATUM
}

Siri Thoresen, Marianne Skogbrott Birkeland, Filip K. Arnberg, Tore Wentzel-Larsen and Ines Blix

\section{Copyright and usage}

(c) The Royal College of Psychiatrists 2019. This is an Open Access article, distributed under the terms of the Creative Commons Attribution-NonCommercial-NoDerivatives licence (http://creativecommons.org/licenses/by-ncnd/4.0/), which permits non-commercial reuse, distribution, and reproduction in any medium, provided the original work is unaltered and is properly cited. The written permission of Cambridge University Press must be obtained for commercial re-use or in order to create a derivative work.

https://doi.org/10.1192/bjo.2018.74, Published by Cambridge University Press, 21 December 2018.

(a)

Men

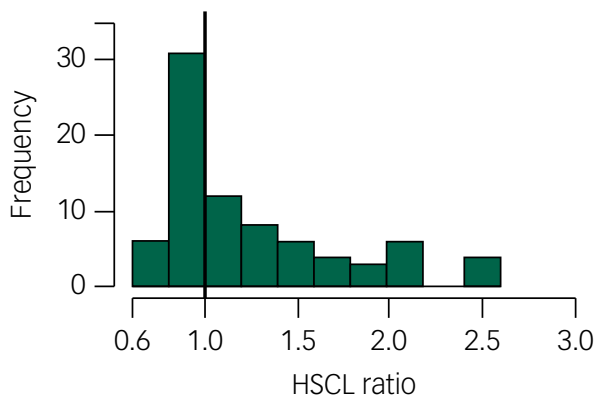

(b)

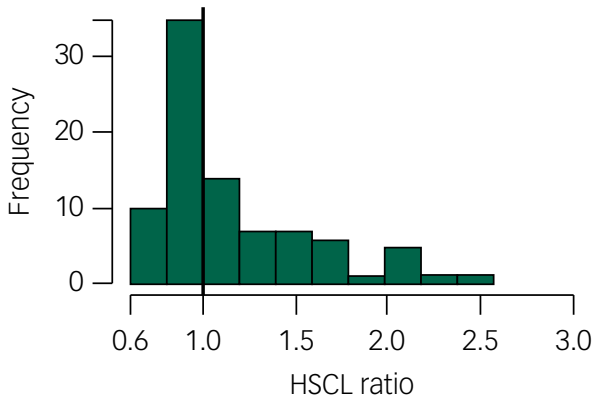

This article was erroneously published with the wrong figures. The actual figures are below.

\section{Reference}

Thoresen S., Birkeland M. S., Arnberg F. K., Wentzel-Larsen T., \& Blix I. (2019). Longterm mental health and social support in victims of disaster: comparison with a general population sample. BJPsych Open, 5(1), e2. Cambridge University Press.

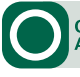
OPEN
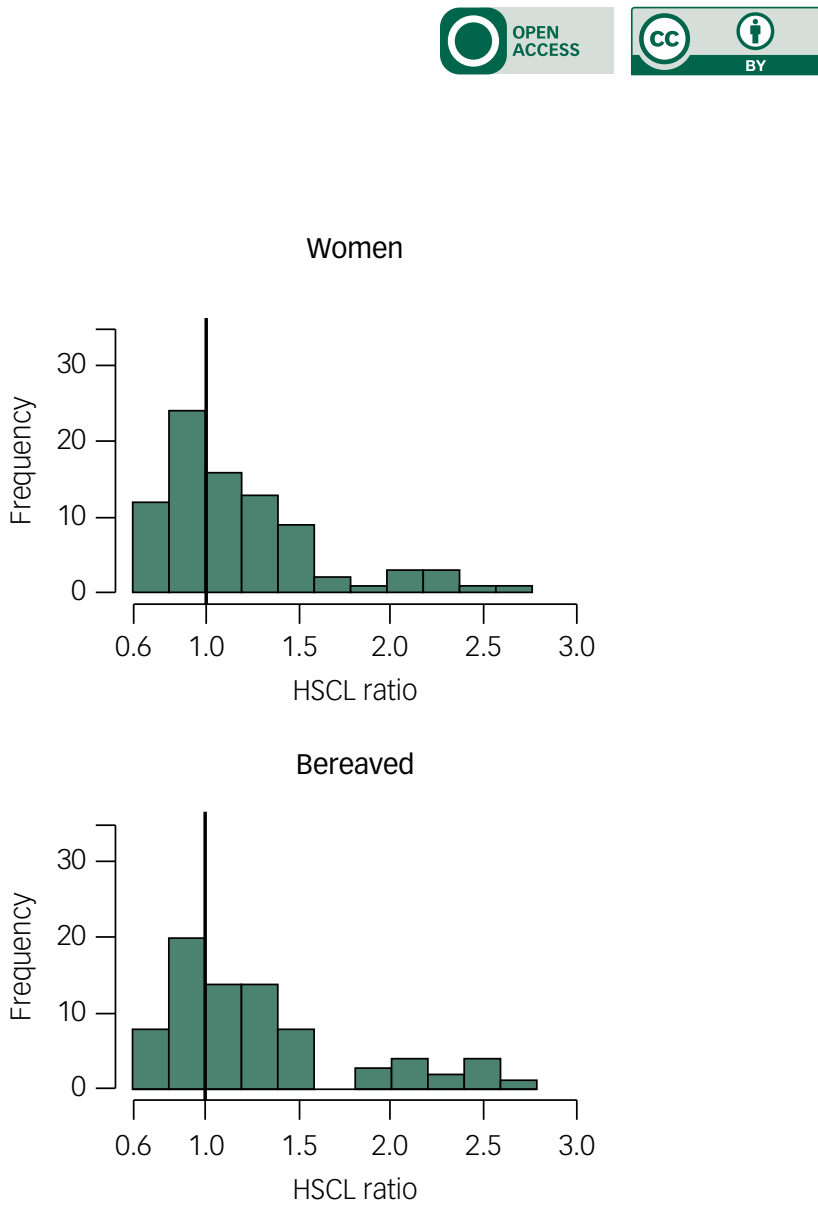

Fig. 1 Ratio between observed and expected anxiety/depression scores (HSCL) in men and women (a) and in the survivors and the bereaved (b). 
(a)

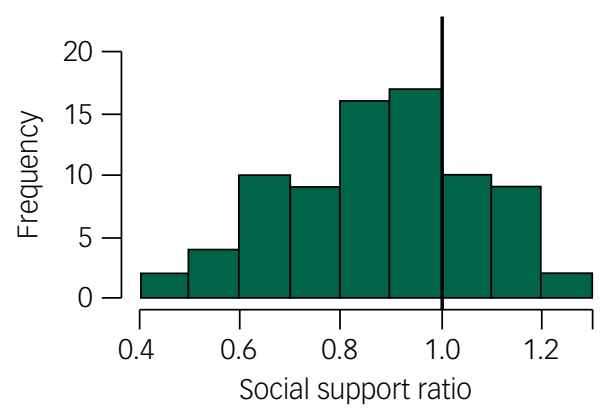

(b)

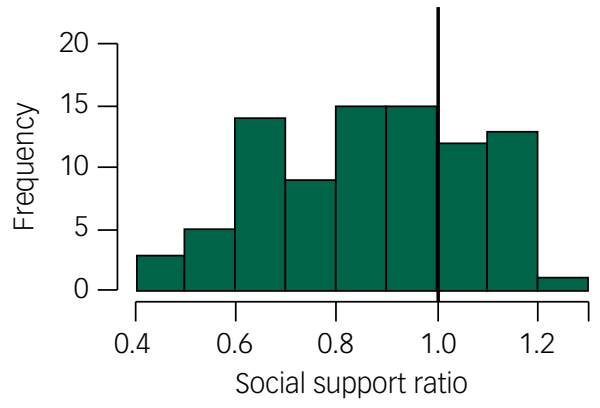

Women

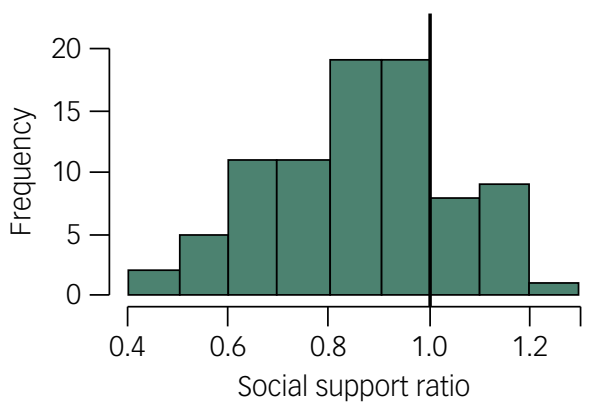

Bereaved

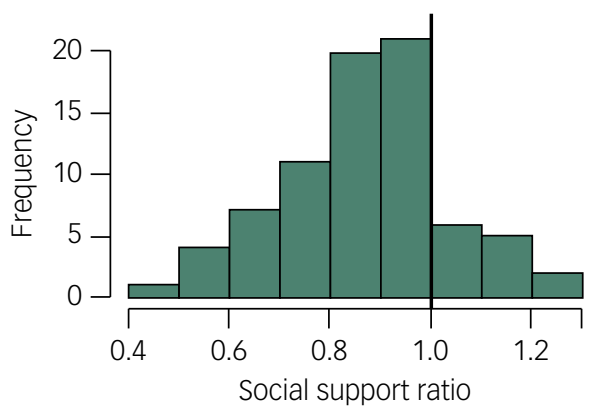

Fig. 2 Ratio between observed and expected perceived social support in men and women (a) and in the survivors and the bereaved (b). 